\title{
The Potential of Emerging Technology for Social Change
}

\author{
Leigh Ellen Potter \\ IDEA Lab, Griffith University \\ Kessels Rd, Nathan 4111 \\ L.Potter@griffith.edu.au
}

\author{
Jake Araullo \\ IDEA Lab, Griffith University \\ Kessels Rd, Nathan 4111 \\ jake.araullo@griffithuni.edu.au
}

\author{
Lewis Carter \\ Idea Lab, Griffith University \\ Kessels Rd, Nathan, 4111 \\ L.Carter@griffith.edu.au
}

\author{
Michelle L. Kaarst-Brown \\ School of Information Studies \\ Syracuse University, NY USA \\ Mlbrow03@syr.edu
}

\begin{abstract}
The purpose of this panel is to explore the potential for emerging technology to engender social change. Technology is transformative, and has already seen innovative application in business and industry, and of course in relation to society and social networking. We will discuss the current state of 'emerging technology', and several perspectives of considerations with emerging technologies and society. We will describe some current applications of emerging technology in a range of fields, in order to identify the potential for emerging technology to support social change. Our goal is to open discussions about opportunities for emerging technology, and practical applications or approaches to how these opportunities can be exploited.
\end{abstract}

\section{CCS Concepts}

Human-centered computing Collaborative and social computing Keywords

Emerging Technology; social change; innovation

\section{INTRODUCTION}

The term 'emerging technology' is used in a range of fields to indicate a new tool or technique within an environment. For the purposes of this panel, emerging technology is defined as a technology that has transformational potential for business, industry or society, regardless of the age of the technology itself; is not yet widespread; and may be emerging in one context, yet established in another (transplanted). Emerging technology is associated with a degree of ambiguity, generated by its emergent nature and the fact that it is not yet established [10]. This problem has been experienced with the traditional diffusion of older technologies, however, we are not seeing a reduction in the radical potential of capabilities and implications.

The Internet of Things has seen mainstream technologies used in new ways, and the advent of new technologies connecting and

Permission to make digital or hard copies of part or all of this work for personal or classroom use is granted without fee provided that copies are not made or distributed for profit or commercial advantage and that copies bear this notice and the full citation on the first page. Copyrights for third-party components of this work must be honored. For all other uses, contact the Owner/Author.

Copyright is held by the owner/author(s).

SIGMIS-CPR '16, June 02-04, 2016, Alexandria, VA, USA

ACM 978-1-4503-4203-2/16/06.

http://dx.doi.org/10.1145/2890602.2890624 interacting. There are emerging technologies such as the Leap Motion controller, Microsoft Kinect, Myo gesture control armband, VTTs InTouch technologies and others providing new ways for people to use and interact with their computers.

Interest in the application of gamification methods, particularly within mobile applications and devices, in relation to emerging technologies is growing [3, 7]. Shortcomings have been identified, particularly in relation to motivation, habit creation and the application of design approaches when interacting with these new technology artefacts [1]. We have new technology, however the innovative application and potential for this technology has not been fully explored.

We tend to think of emerging technologies as following a standard developmental or diffusion pattern. However, every technology has its own "s" or developmental and diffusion life cycle in different industries, countries, and societal groups. We see this in research on early versus late adopters [9], aging and older adults [2], and in studies of aboriginal or Native American communities where social structures and power relationships can be disrupted by new technologies [11]. As we see increasingly heterogeneous social groups and sub-cultures in local and global society with different needs and goals, we may need to think not only about the potential of new technologies, but also how established technologies in one setting, may challenge social structures in another. At the same time, there is a presumption that with social media, audiences are becoming more homogeneous, when in fact, globalization and socio-economic, educational, generational, and other factors increase the likelihood of heterogeneous audiences for both emerging and transplanted technologies.

These new devices and new methods of interaction may provide an opportunity to improve societies and the lives of the communities within these societies, however, there are risks along with potential rewards. The questions to be answered are, "What can we achieve, and how can we achieve it?"

The aim of this panel is to explore innovative practices and approaches for the design and application of emerging technologies, and their potential for supporting social change. We will discuss examples of work currently underway in this area, and seek to generate discussions regarding the potential for emerging technology application, and ideas for future directions.

\section{OVERVIEW OF PRESENTATIONS}

Leigh Ellen Potter will discuss user experience when interacting with emerging technology. These technologies often enable new interaction mechanisms through the use of innovative device 
capabilities [8]. Established interaction mechanisms may not work effectively with these emerging technologies, affecting the user experience. Consideration of the user experience when designing emerging technology to support social change is vital. She will describe work currently underway in the Idea Lab, such as Seek and Sign [6].

Lewis Carter will discuss a project exploring design conventions for the emerging head mounted virtual reality devices, such as the Oculus Rift and the HTC Vive. Virtual reality comes with its own strengths and weaknesses, and these must be taken into account when designing applications to produce the best possible experience for players. Lewis will discuss research exploring the application of design techniques that maximize the new capabilities offered by emerging technologies.

Jake Araullo will discuss the application of wearable technology for motivating senior citizens to be more active. Opportunities are present for emerging technologies to promote and engage seniors in physical activity. There is a potential for wearables to support social change in this area, in terms of boosting quality-of-life, core health, self-efficacy and autonomy in this growing segment of the population. Jake will discuss research in this area, including the potential and limitations of emerging technology when working with seniors.

Michelle Kaarst-Brown will share a cultural analysis technique used as part of an "anticipatory design" approach engaged in before beginning development of a digital heritage preservation system for the Choctaw Nation of Oklahoma. She applied the theory of archetypal "IT Cultures" $[4,5]$ to engage a sample of culturally respected tribal elders. Unlike traditional requirements analysis, the goal was to better understand cultural concerns and anticipatory design considerations in advance of any developmental efforts for this "'new' technology opportunity for the Choctaw." A key finding was the importance of "situated symbolism" to distance from the technological features to engage in design considerations that could affect social change.

\section{PRESENTERS}

Leigh Ellen Potter is a lecturer in the School of Information and Communication Technology, Griffith University in Australia, and the Director of the Idea lab - Innovative Design and Emerging Application. Her industry background in business analysis and user experience informed her $\mathrm{PhD}$ research, exploring the attributes of IT professionals, and what draws them to the industry. Her research interests include user centred design and usability, and emerging technology. She is team lead for several research projects through the Idea lab.

Lewis Carter is a $\mathrm{PhD}$ Student at Griffith University in Australia. He has a degree in Software Engineering with Honours, and has a strong interest in game design. His research looks at consumer virtual reality and how current game design principles need to adapt to better suit the technology. He has completed a research project identifying preliminary design heuristics for this type of VR technology. Lewis works with the Idea lab, and is currently project lead for the development of a gaming application for consumer virtual reality technologies.

Jake Araullo is a $\mathrm{PhD}$ Candidate at the Griffith University Idea Lab. He has a degree in Software Engineering with Honours. Jake's research area is around promoting physical activity in seniors using emerging technologies. In the past, Jake has worked in startup environments and in research, and has studied best usability practices with emerging technologies such as Leap Motion and Oculus Rift. Emerging technology provides novel interaction opportunities and Jake's research attempts to harness this, with the aim of creating macro-level positive change in physical activity for older populations.

Michelle Kaarst-Brown is an Associate Professor at the School of Information Studies, Syracuse University. Much of her recent research has been in partnership with practitioners in government, industry, and education. Drawing upon prior management and consulting experience, her research studies how social, cultural, knowledge and generational factors influence IT governance, the IT workforce, and technology adoption. Dr. Kaarst-Brown has published in a number of top academic and business journals including MIS Quarterly, IT\&P, the Journal of Strategic Information Systems, and MIS Quarterly Executive. She serves as a Senior Editor for MIS Quarterly Executive.

\section{REFERENCES}

[1] Bice, M.R., Ball, J.W. and McClaran, S. 2015. Technology and physical activity motivation. International Journal of Sport and Exercise Psychology. (Apr 2015), 1-10.

[2] Birkland, J.H. and Kaarst-Brown, M.L. 2012. It's All a Matter of Choice: Understanding society's expectations of older adult ICT use from a birth cohort perspective. Cultural Attitudes towards Technology and Communication (CATaC) (Aarhus, Denmark, 2012).

[3] Buttussi, F. and Chittaro, L. 2010. Smarter Phones for Healthier Lifestyles: An Adaptive Fitness Game. IEEE Pervasive Computing. 9, 4 (Oct. 2010), 51-57.

[4] Kaarst-Brown, M.L. 2005. Understanding an Organization's View of the CIO: The role of assumptions about IT. MISQ Executive. 4, 2 (2005), 287-301.

[5] Kaarst-Brown, M.L. and Robey, D. 1999. More on Myth, Magic and Metaphor: Cultural Insights into the Management of Information Technology in Organizations. Information Technology and People. 12, 2 (1999), 192-217.

[6] Korte, J., Potter, L.E.C. and Nielsen, S.H. 2015. An experience in requirements prototyping with young deaf children. Journal of Usability Studies. 10, 4 (2015), 195214.

[7] Madeira, R.N., Costa, L. and Postolache, O. 2014. PhysioMate - Pervasive physical rehabilitation based on NUI and gamification. 2014 International Conference and Exposition on Electrical and Power Engineering (EPE) (Oct. 2014), 612-616.

[8] Potter, L.E., Araullo, J. and Carter, L. 2013. The Leap Motion controller. Proceedings of the 25th Australian Computer-Human Interaction Conference on Augmentation, Application, Innovation, Collaboration OzCHI '13 (Adelaide, Australia, Nov. 2013), 175-178.

[9] Rogers, E. 2003. Diffusion of Innovation. Simon and Schuster.

[10] Rotolo, D., Hicks, D. and Martin, B. 2015. What Is an Emerging Technology? Research Policy. 44, 10 (2015), 1827-1843.

[11] Roy, L. and Raitt, D. 2003. The impact of IT on indigenous peoples. The Electronic Library. 21, 5 (2003), 411-413. 